
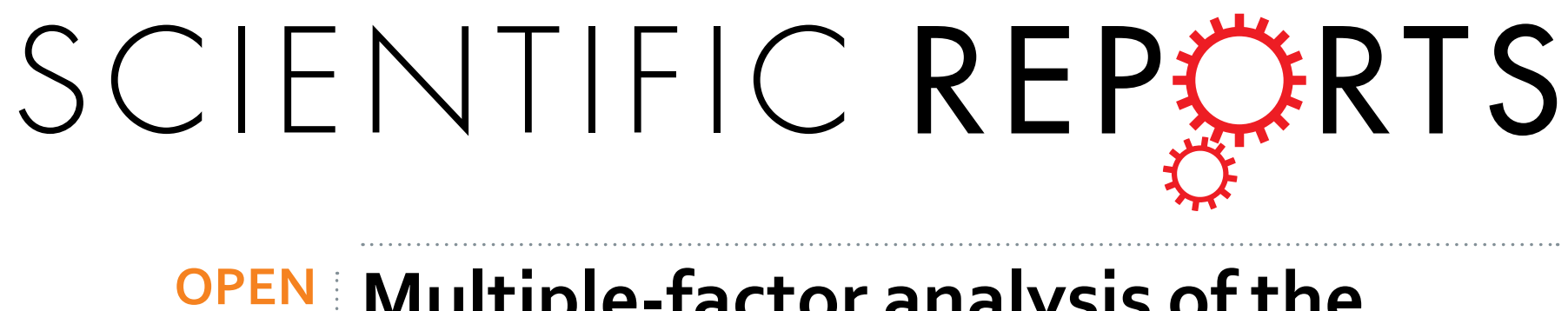

\title{
Multiple-factor analysis of the
} first radioactive iodine therapy in post-operative patients with

Received: 04 May 2016

Accepted: 21 September 2016

Published: 10 October 2016

\section{differentiated thyroid cancer for achieving a disease-free status}

Na Liu, Zhaowei Meng, Qiang Jia, Jian Tan, Guizhi Zhang, Wei Zheng, Renfei Wang, Xue Li, Tianpeng Hu, Arun Upadhyaya, Pingping Zhou \& Sen Wang

${ }^{131}$ I treatment is an important management method for patients with differentiated thyroid cancer (DTC). Unsuccessful ${ }^{131}$ I ablation drastically affects the prognosis of the patients. This study aimed to analyze potential predictive factors influencing the achievement of a disease-free status following the first ${ }^{131}$ I therapy. This retrospective review included 315 DTC patients, and multiple factors were analyzed. Tumor size, pathological tumor stage, lymph node (LN) metastasis, distant metastasis, American Thyroid Association recommended risks, pre-ablation thyroglobulin ( $\mathrm{Tg}$ ), and thyroid stimulating hormone (TSH) displayed significant differences between unsuccessful and successful group. Cutoff values of Tg and TSH to predict a successful outcome were $3.525 \mathrm{ng} / \mathrm{mL}$ and $99.700 \mathrm{ulU} / \mathrm{ml}$ by receiver operating characteristic curves analysis. Binary logistic regression analysis showed that tumor stage $\mathrm{T} 3$ or T4, LN metastasis to N1b station, intermediate and high risks, preablation Tg $\geq 3.525 \mathrm{ng} / \mathrm{ml}$ and TSH $<99.700 \mu \mathrm{IU} / \mathrm{mL}$ were significantly associated with unsuccessful outcomes. Logistic regression equation for achieving a disease-free status could be rendered as: $y$ (successful treatment) $=-0.270-0.503 \mathrm{X}_{1}\left(\mathrm{LN}\right.$ metastasis) $-0.236 \mathrm{X}_{2}(\mathrm{Tg})+0.015 \mathrm{X}_{3}(\mathrm{TSH})$. This study demonstrated $\mathrm{LN}$ metastasis, pre-ablation Tg and TSH were the most powerful predictors for achieving a disease-free status by the first ${ }^{131}$ t therapy.

In recent years, the incidence of thyroid cancer is rapidly increasing, and about $90 \%$ of which is differentiated thyroid cancer (DTC), including papillary thyroid cancer (PTC) and follicular thyroid cancer (FTC) ${ }^{1}$. For the optimal management of DTC, total thyroidectomy, post-operative radioactive iodine $\left({ }^{131} \mathrm{I}\right)$ therapy and thyroid stimulating hormone (TSH) suppression treatment are the three most essential methods ${ }^{2-5}$. Theoretically, ${ }^{131} \mathrm{I}$ therapy is thought to reduce the recurrence and mortality rate in DTC patients by destroying microscopic residual tumor foci, which also facilitates early detection of recurrence by enhancing the sensitivity and reliability of serum thyroglobulin (Tg) and ${ }^{131}$ I whole-body scan (WBS $)^{5-7}$. However, there is a lack of consensus among guidelines about the optimal ${ }^{131} \mathrm{I}$ dose for ablation ${ }^{3-5}$, although the most recent meta-analysis favored the empiric $100 \mathrm{mCi}^{6,7}$.

Although ${ }^{131} \mathrm{I}$ therapy is generally considered safe, some potential complications could happen. For instance, a large dose of ${ }^{131}$ I could increase the risk of dysfunction of several body organs, including gastrointestinal, pulmonary, and hematopoietic systems, salivary glands, and gonads ${ }^{4,5,8}$. Hakala et al. ${ }^{9}$ even reported that for young patients ( $<40$ years), the risk of secondary malignancies would dramatically increase. More importantly, the use of ${ }^{131} \mathrm{I}$ for remnant ablation to reduce the risk of recurrence following thyroidectomy in low risk DTC patients remained controversial ${ }^{10,11}$. On the other hand, recent evidence showed that for low risk DTC patients, low dose of ${ }^{131}$ I therapy could successfully achieve complete ablation ${ }^{12,13}$. Therefore, it is imperative that clinicians should utilize individualized and optimized ${ }^{131} \mathrm{I}$ dose for the management of DTC patients to balance the risks and benefits of this important therapy. and requests for materials should be addressed to Z.M. (email: jamesmencius@163.com) 
Predictors of DTC prognosis have been investigated by several studies, although the values of different parameters are inconsistent among them. For instance, pre-ablation stimulated Tg is known to be a good predictor of successful ablation in DTC patients ${ }^{14}$. Pre-ablation Tg has also been demonstrated as an important indicator for predicting persistence or recurrence during follow-up ${ }^{15-17}$. However, cut-off values of Tg for successful ablation or recurrence prediction were quite different among the above mentioned studies. A second good example is about TSH. Guidelines recommended that DTC patients receiving ${ }^{131}$ I therapy should have a serum TSH level of higher than $30 \mu \mathrm{IU} / \mathrm{mL}^{2-5}$. However, Vrachimis et al. ${ }^{18}$ demonstrated that endogenous TSH levels at the time of ${ }^{131}$ I ablation did not influence ablation success, recurrence-free survival or differentiated thyroid cancer-related mortality. Hasbek et al. ${ }^{19}$ also found that a high TSH level alone was not a factor for the success of ablation. So, a comprehensive research to assess possible predictive factors would be valuable to the subject.

The goal of this study is to analyze potential predictive values of various clinical factors to achieve a disease-free status by the first ${ }^{131}$ I therapy in post-operative DTC patients.

\section{Results}

Data comparisons of DTC patients with or without disease-free status. A total of 315 DTC patients were recruited in our analysis. Among them, 118 patients $(37.5 \%)$ achieved disease-free status, while 197 patients $(62.5 \%)$ did not. Patient's age ranged from 18 to 77 years old ( $47.5 \pm 12.2$ years). Clinical characteristics of the 315 patients were summarized in Table 1. Between the unsuccessful and successful ablation outcome groups, age and gender had no statistical differences. Most of the patients were PTC, accounting for $100.00 \%$ of the successful group, and $97.46 \%$ of the unsuccessful group. Pathology showed no statistical significance. Capsular invasion, American Joint Committee on Cancer (AJCC) tumor-node-metastasis (TNM) staging system, time interval between surgery and ${ }^{131} \mathrm{I}$ therapy also had no differences. Tumor size (diameter $>1 \mathrm{~cm}$ versus $\leq 1 \mathrm{~cm})\left(\mathrm{X}^{2}=4.668, \mathrm{P}=0.031\right)$, pathological tumor stage $\left(\mathrm{X}^{2}=13.193, \mathrm{P}=0.004\right)$, lymph node $(\mathrm{LN})$ metastasis $\left(\mathrm{X}^{2}=18.192, \mathrm{P}<0.001\right)$, distant metastasis (Fisher exact test, $\left.\mathrm{P}=0.001\right)$, American Thyroid Association (ATA) recommended risks $\left(\mathrm{X}^{2}=17.453, \mathrm{P}<0.001\right)$, pre-ablation $\mathrm{Tg}\left(\mathrm{t}^{\prime}=6.900, \mathrm{P}<0.001\right)$ and $\mathrm{TSH}\left(\mathrm{t}^{\prime}=-3.367\right.$, $\mathrm{P}=0.001)$ displayed significant differences.

Diagnostic values of Tg and TSH for a successful therapy. For continuous parameters (pre-ablation Tg and TSH), receiver operating characteristic (ROC) curves were conducted (Fig. 1). A cutoff value of $3.525 \mathrm{ng} / \mathrm{ml}$ for pre-ablation $\mathrm{Tg}$ could be used to differentiate successful and unsuccessful ablation with a sensitivity of 77.12\%, specificity of $74.12 \%$, PPV (positive predictive value) of $64.09 \%$, and negative predictive value (NPV) of $84.39 \%$. A cutoff value of $99.700 \mu \mathrm{IU} / \mathrm{ml}$ for TSH could distinguish successful and unsuccessful ablation with a sensitivity of $57.63 \%$, specificity of $57.46 \%$, PPV of $44.74 \%$ and NPV of $69.33 \%$ (Table 2).

Risk assessments for a therapeutic failure. Next, we used a binary logistic regression analysis to identify risk factors associated with therapeutic failure. No risks were found among age, gender, capsular invasion, TNM stage and time interval between surgery and ${ }^{131} \mathrm{I}$. In contrast, tumor stage T3 or T4, LN metastasis to lateral cervical region (N1b) station, intermediate and high risks, pre-ablation $\mathrm{Tg} \geq 3.525 \mathrm{ng} / \mathrm{ml}$ and $\mathrm{TSH}<99.700 \mu \mathrm{IU} / \mathrm{mL}$ were significantly associated with a therapeutic failure (Table 3).

Equation for achieving a disease-free status. Using an unconditioned logistic regression analysis, LN metastasis, pre-ablation Tg level and pre-ablation TSH level showed significant associations with the disease-free status and were included in the regression model. The equation for achieving a disease-free status by the first ${ }^{131} \mathrm{I}$ therapy could be rendered as: $\mathrm{y}$ (successful therapeutic outcome $)=-0.270-0.503 \mathrm{X}_{1}(\mathrm{LN}$ metastasis $)-0.236 \mathrm{X}_{2}$ (pre-ablation Tg level) $+0.015 \mathrm{X}_{3}$ (pre-ablation TSH level).

\section{Discussion}

Although a number of studies investigated the predictors of DTC prognosis, inconsistency existed about values of various predictors ${ }^{14-20}$. The merit of the current study is that it examined all the predictors within a comprehensive statistical framework. This retrospective study demonstrated that LN metastasis, pre-ablation Tg and TSH were the most powerful predictive factors for a successful ${ }^{131}$ I ablative outcome. Existence of LN metastasis, high pre-ablation Tg level and low pre-ablation TSH level in patients with DTC were associated with increased risk for therapeutic failure.

The incidence of PTC is usually much higher than FTC in clinic. PTC is prone to LN metastasis at an early stage with no definite relationship with primary lesion size. Even when the primary tumor is $\leq 1 \mathrm{~cm}, \mathrm{LN}$ metastasis could still happen often in PTC ${ }^{21,22}$. Most scholars believe that the first station of LN metastases is the central region (N1a), and then the second station to the N1b. However, lateral LN metastasis without central LN involvement could also occur in patients with PTC $^{23}$. Several studies showed that for patients (especially age $\geq 45$ years), LN metastasis was an indicative factor for high recurrence rate and low survival rate. Compared with $\mathrm{N} 1$ a station, the 5 year survival rate was significantly lower in N1b station ${ }^{24-26}$. Moreover, previous studies ${ }^{20,27,28}$, including one case report from our institution ${ }^{22}$, found that extensive metastases would affect the overall therapeutic effectiveness of ${ }^{131} \mathrm{I}$. In our study, after multiple-factor analysis, we found that compared with DTC patients without LN metastasis (N0), no significant difference of disease-free status rate was achieved in the N1a patients [odds ratio $(\mathrm{OR})=1.406, \mathrm{P}=0.185$ ]. However, significantly higher risk of unsuccessful therapeutic outcome was found in $\mathrm{N} 1 \mathrm{~b}$ patients $(\mathrm{OR}=4.783, \mathrm{P}<0.001)$. In the logistic regression analysis, $\mathrm{LN}$ metastasis had a coefficient of -0.503 , which indicated positive LN metastasis would increase the risk of therapeutic failure. Moreover, in our study, 14 DTC patients had distant metastases, none of them achieved a disease-free status by the first ${ }^{131}$ I therapy.

The clinical value of Tg has been reported in many studies, especially with regard to DTC disease progression or recurrence $\mathrm{e}^{14-17,29}$. Some studies have shown the relationship between pre-ablation Tg and successful ablation. For example, Lim et al. ${ }^{29}$ analyzed various predictors for successful ablation and disease-free status using 


\begin{tabular}{|c|c|c|c|c|}
\hline Factors & $\begin{array}{l}\text { Unsuccessful outcome } \\
\text { [Case number (\%)] }\end{array}$ & $\begin{array}{l}\text { Successful outcome } \\
\text { [Case number (\%)] }\end{array}$ & Statistics & P values \\
\hline \multicolumn{5}{|l|}{ Age } \\
\hline$<45$ & $80(40.61 \%)$ & $39(33.05 \%)$ & $\mathrm{X}^{2}=1.794$ & 0.180 \\
\hline$\geq 45$ & $117(59.39 \%)$ & $79(66.95 \%)$ & & \\
\hline \multicolumn{5}{|l|}{ Gender } \\
\hline Male & $53(26.90 \%)$ & $23(19.49 \%)$ & $\mathrm{X}^{2}=2.215$ & 0.137 \\
\hline Female & $144(73.10 \%)$ & $95(80.51 \%)$ & & \\
\hline \multicolumn{5}{|l|}{ Size of tumor } \\
\hline$\leq 1 \mathrm{~cm}$ & $39(19.80 \%)$ & $36(30.51 \%)$ & $\mathrm{X}^{2}=4.668$ & 0.031 \\
\hline$>1 \mathrm{~cm}$ & $158(80.20 \%)$ & $82(69.49 \%)$ & & \\
\hline \multicolumn{5}{|l|}{ Pathology } \\
\hline Papillary thyroid cancer & 192(97.46\%) & $118(100.00 \%)$ & Fisher exact test & 0.161 \\
\hline Follicular thyroid cancer & $5(2.54 \%)$ & $0(0.00 \%)$ & & \\
\hline \multicolumn{5}{|l|}{ Capsular invasion } \\
\hline No & $113(57.36 \%)$ & $79(66.95 \%)$ & $\mathrm{X}^{2}=2.851$ & 0.091 \\
\hline Yes & $84(42.64 \%)$ & $39(33.05 \%)$ & & \\
\hline \multicolumn{5}{|l|}{ Pathological tumor stage } \\
\hline $\mathrm{T} 1$ & $65(32.99 \%)$ & $59(50.00 \%)$ & $\mathrm{X}^{2}=13.193$ & 0.004 \\
\hline $\mathrm{T} 2$ & $32(16.24 \%)$ & $19(16.10 \%)$ & & \\
\hline $\mathrm{T} 3$ & $87(44.16 \%)$ & $39(33.05 \%)$ & & \\
\hline $\mathrm{T} 4$ & $13(6.60 \%)$ & $1(0.85 \%)$ & & \\
\hline \multicolumn{5}{|l|}{$\mathrm{LN}^{*}$ metastasis } \\
\hline N0 & $70(35.53 \%)$ & $62(52.54 \%)$ & $\mathrm{X}^{2}=18.192$ & $<0.001$ \\
\hline Nla & $73(37.06 \%)$ & $46(38.98 \%)$ & & \\
\hline N1b & $54(27.41 \%)$ & $10(8.47 \%)$ & & \\
\hline \multicolumn{5}{|l|}{ Distant metastasis } \\
\hline M0 & $183(92.89 \%)$ & $118(100.00 \%)$ & Fisher exact test & 0.001 \\
\hline M1 & $14(7.11 \%)$ & $0(0.00 \%)$ & & \\
\hline \multicolumn{5}{|l|}{$\mathrm{TNM}^{*}$ stage } \\
\hline Stage I & $100(50.76 \%)$ & $63(53.39 \%)$ & $\mathrm{X}^{2}=4.468$ & 0.215 \\
\hline Stage II & $12(6.09 \%)$ & $8(6.78 \%)$ & & \\
\hline Stage III & $50(25.38 \%)$ & $36(30.51 \%)$ & & \\
\hline Stage IV & $35(17.77 \%)$ & $11(9.32 \%)$ & & \\
\hline \multicolumn{5}{|l|}{ ATA risks* } \\
\hline Low risk & $57(28.93 \%)$ & $55(46.61 \%)$ & $\mathrm{X}^{2}=17.453$ & $<0.001$ \\
\hline Intermediate risk & $119(60.41 \%)$ & $62(52.54 \%)$ & & \\
\hline High risk & $21(10.66 \%)$ & $1(0.85 \%)$ & & \\
\hline \multicolumn{5}{|c|}{ Time interval of surgery and ${ }^{131} \mathrm{I}$ therapy } \\
\hline$<3$ months & $165(83.76 \%)$ & $100(84.75 \%)$ & $\mathrm{X}^{2}=0.054$ & 0.816 \\
\hline$\geq 3$ months & $32(16.24 \%)$ & $18(15.25 \%)$ & & \\
\hline Pre-ablation $\mathrm{Tg}^{\star}(\mathrm{ng} / \mathrm{ml})$ & $38.40 \pm 72.91$ & $2.50 \pm 3.29$ & $\mathrm{t}^{\prime}=6.900$ & $<0.001$ \\
\hline Pre-ablation $\mathrm{TSH}^{\star}(\mathrm{uIU} / \mathrm{ml})$ & $91.98 \pm 42.89$ & $107.18 \pm 36.11$ & $\mathrm{t}^{\prime}=-3.367$ & 0.001 \\
\hline
\end{tabular}

Table 1. Comparisons of characteristics of the patients. ${ }^{\star} \mathrm{LN}=$ lymph node, $\mathrm{TNM}$ stage $=$ American Joint Committee on Cancer tumor-node-metastasis staging system, ATA risks = American Thyroid Association risks, $\mathrm{Tg}=$ thyroglobulin, $\mathrm{TSH}=$ thyroid stimulating hormone.

univariate and multivariate analyses, and determined that a Tg value greater than $5 \mathrm{ng} / \mathrm{mL}$ was the most powerful predictor for ablation failure. A meta-analysis including 3947 patients demonstrated that the pre-ablation Tg was a useful negative predictor for persistent and recurrent DTC, in particular NPV was $94 \%$ if pre-ablation Tg level was less than $10 \mathrm{ng} / \mathrm{mL}^{17}$. Gonzalez et al..$^{15}$ conducted an investigation on $133 \mathrm{DTC}$ patients and revealed that a pre-ablation Tg of less than $8.55 \mathrm{ng} / \mathrm{mL}$ could predict remission of disease in 18 to 24 months after ${ }^{131} \mathrm{I}$ therapy with a sensitivity of $88 \%$, specificity of $72 \%$, PPV of $47 \%$ and NPV of $95 \%$, and area under the ROC curve of 0.872 . In our study, a baseline-stimulated Tg value of $3.525 \mathrm{ng} / \mathrm{mL}$ was identified as the optimum cut-off by the ROC analysis. If Tg was lower than $3.525 \mathrm{ng} / \mathrm{mL}$, the disease-free status by the first ${ }^{131} \mathrm{I}$ therapy could be predicted with an accuracy of $75.24 \%$. In the logistic regression equation, $\mathrm{Tg}$ had a coefficient of -0.236 , which indicates the low pre-ablation Tg level could predict the possible disease-free status. Hence, measurement the pre-ablation Tg in patients with DTC is important.

We also found that pre-ablation TSH level was an important factor for complete remission by the first ${ }^{131}$ I therapy. ATA and European guidelines recommended a dogma that DTC patients receiving ${ }^{131}$ I therapy should have a 

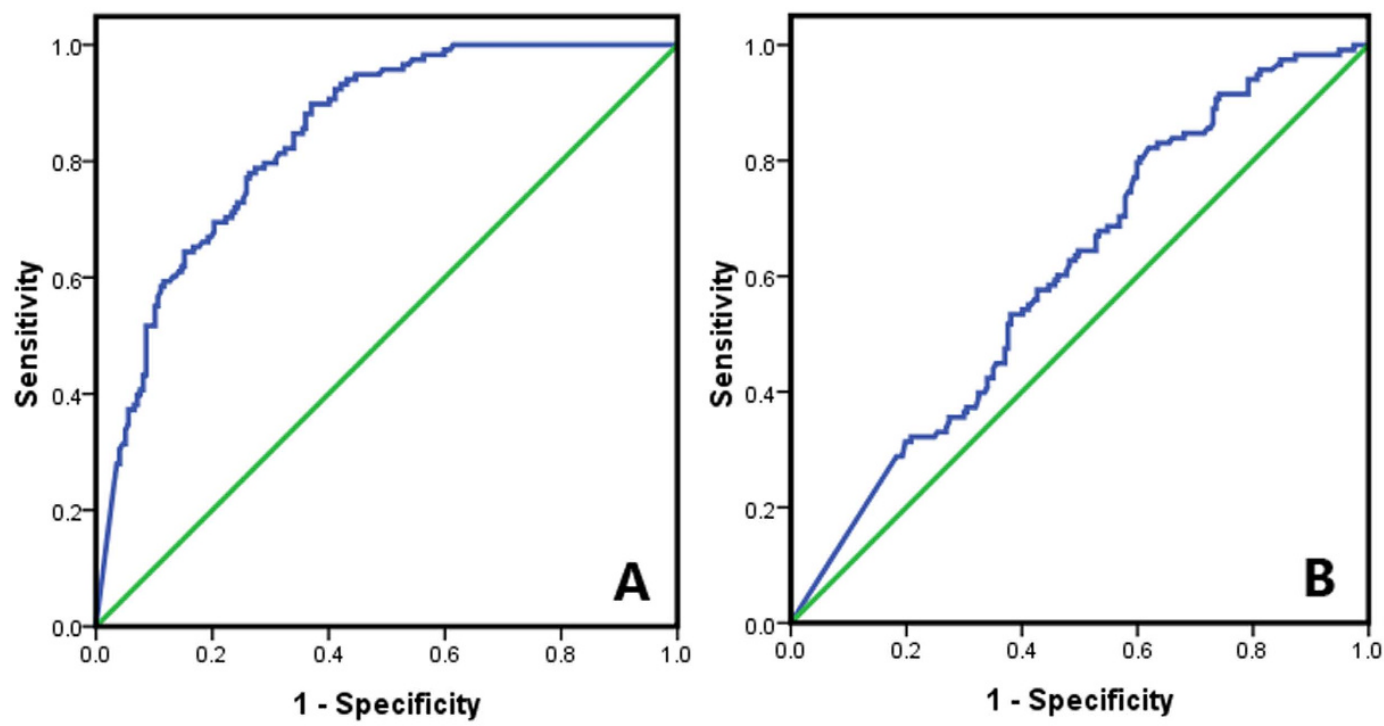

Figure 1. Diagnostic values of pre-ablation thyroglobulin (A) and thyroid stimulating hormone (B) analyzed by receiver operating characteristic curves.

\begin{tabular}{|l|c|c|c|c|c|c|c|c|}
\hline & Cutoff values & Accuracy & Sensitivity & Specificity & PPV $^{*}$ & NPV $^{*}$ & AUC $^{*}\left(\mathbf{9 5} \% \mathbf{C I}^{*}\right)$ & P values \\
\hline Pre-ablation $\mathrm{Tg}^{*}$ & $3.525 \mathrm{ng} / \mathrm{mL}$ & $75.24 \%$ & $77.12 \%$ & $74.12 \%$ & $64.09 \%$ & $84.39 \%$ & $0.843(0.801-0.885)$ & $<0.001$ \\
\hline Pre-ablation $\mathrm{TSH}^{*}$ & $99.700 \mu \mathrm{IU} / \mathrm{ml}$ & $57.46 \%$ & $57.63 \%$ & $57.46 \%$ & $44.74 \%$ & $69.33 \%$ & $0.605(0.542-0.667)$ & 0.002 \\
\hline
\end{tabular}

Table 2. Diagnostic and predictive values of pre-ablation $\mathrm{Tg}^{\star}$ and $\mathrm{TSH}^{\star}$ for a successful therapeutic outcome. ${ }^{\star} \mathrm{Tg}=$ thyroglobulin, $\mathrm{TSH}=$ thyroid stimulating hormone, $\mathrm{PPV}=$ positive predictive value, $\mathrm{NPV}=$ negative predictive value, $\mathrm{AUC}=$ area under the curve, $\mathrm{CI}=$ confidence interval.

serum TSH level of higher than $30 \mu \mathrm{IU} / \mathrm{mL}^{2-5}$. Historically, it was first reported in 1977 by Edmonds et al. ${ }^{30}$ that DTC patients who failed to produce a TSH level of $>30 \mu \mathrm{IU} / \mathrm{mL}$ by a postoperative levo-thyroxine (LT4) withdrawal preparation showed much lower rates of successful ${ }^{131}$ I ablation. However, several recent studies showed that TSH stimulation for postoperative ${ }^{131}$ I ablation was not important and did not influence the ablation success rate $^{18,19}$. In our study protocol, all patients were ideally required to have a TSH level up to $30 \mu \mathrm{IU} / \mathrm{mL}$ before treatment, yet there were 19 patients who didn't meet this requirement. We gave them $100 \mathrm{mCi}$ of ${ }^{131} \mathrm{I}$, nonetheless. As a result, in these 19 patients, only 2 achieved a disease-free status after the first ${ }^{131}$ I therapy. In the 17 patients who were not successfully ablated, 2 had distant metastases, and 4 were in N1b stage. This result indicates that remaining functional benign and malignant thyrocytes could be one main reason why their TSH levels failed to reach the required threshold.

Then how to explain this phenomenon after all? We believed that for one thing, it was possible that thyroid remnant size and/or DTC metastatic lesions could be major factors influencing TSH levels and ablation success rates. For another, several other factors could also influence TSH. For instance, different durations of LT4 withdrawal could affect TSH level. It could be difficult to assure that all patients had the same duration of LT4 withdrawal, since not all of them were very compliant. It is also possible that older patients tend to have a lower ability to produce TSH. In fact, TSH response was found to diminish with age in DTC patients under LT4 therapy ${ }^{31}$. In our study, we found pre-ablation TSH had a threshold value of $99.7 \mu \mathrm{IU} / \mathrm{mL}$ to predict successful ablation with a sensitivity of $57.63 \%$ and a specificity of $57.46 \%$. This diagnostic capability was not sufficient, and there was a large overlap in pre-ablation TSH in different groups of patients. Therefore, based on the above evidence, we believe TSH should be considered a second line indicative value and it should not be classified as a strong predictor for successful ablation.

This study has several limitations. First, our study was retrospective in nature. Second, we had only a small sample of 315 patients who fulfilled our inclusion criteria. Third, factors such as distant metastasis and FTC were not analyzed in detail due to small sample scale. Further large-scale prospective studies are needed.

\section{Conclusion}

This study revealed that LN metastasis, pre-ablation Tg and TSH were the most powerful predictors for achieving a disease-free status by the first ${ }^{131}$ I therapy. Patients with LN metastasis, high pre-ablation Tg level and low pre-ablation TSH would be unlikely to achieve a disease-free status.

\section{Materials and Methods}

Patients. We retrospectively reviewed the DTC patients' database from the year 2010 to 2015 archive of the Department of Nuclear Medicine, Tianjin Medical University General Hospital. All included patients received 


\begin{tabular}{|c|c|c|}
\hline Factors & $\mathrm{OR}^{*}\left(95 \% \mathrm{CI}^{*}\right)$ & P values \\
\hline \multicolumn{3}{|l|}{ Age } \\
\hline$<45$ & 1 & \\
\hline$\geq 45$ & $0.722(0.448-1.164)$ & 0.180 \\
\hline \multicolumn{3}{|l|}{ Gender } \\
\hline Female & 1 & \\
\hline Male & $1.520(0.874-2.645)$ & 0.138 \\
\hline \multicolumn{3}{|l|}{ Size of tumor } \\
\hline$\leq 1 \mathrm{~cm}$ & 1 & \\
\hline$>1 \mathrm{~cm}$ & $1.779(1.051-3.009)$ & 0.032 \\
\hline \multicolumn{3}{|l|}{ Capsular invasion } \\
\hline No & 1 & \\
\hline Yes & $1.506(0.935-2.424)$ & 0.092 \\
\hline \multicolumn{3}{|c|}{ Pathological tumor stage } \\
\hline $\mathrm{T} 1$ & 1 & \\
\hline $\mathrm{T} 2$ & $1.529(0.784-2.982)$ & 0.213 \\
\hline T3 & $2.025(1.208-3.394)$ & 0.007 \\
\hline $\mathrm{T} 4$ & $11.800(1.498-92.978)$ & 0.019 \\
\hline \multicolumn{3}{|l|}{$\mathrm{LN}^{*}$ metastasis } \\
\hline N0 & 1 & \\
\hline N1a & $1.406(0.850-2.324)$ & 0.185 \\
\hline N1b & $4.783(2.245-10.190)$ & $<0.001$ \\
\hline \multicolumn{3}{|l|}{ TNM $^{*}$ stage } \\
\hline Stage I & 1 & \\
\hline Stage II & $0.945(0.366-2.440)$ & 0.907 \\
\hline Stage III & $0.875(0.514-1.489)$ & 0.623 \\
\hline Stage IV & $2.005(0.949-4.232)$ & 0.068 \\
\hline \multicolumn{3}{|l|}{ ATA risks* } \\
\hline Low risk & 1 & \\
\hline Intermediate risk & $1.852(1.145-2.996)$ & 0.012 \\
\hline High risk & $20.263(2.263-155.837)$ & 0.004 \\
\hline \multicolumn{3}{|c|}{ Time interval between surgery and ${ }^{131} \mathrm{I}$ therapy } \\
\hline$<3$ months & 1 & \\
\hline$\geq 3$ months & $1.077(0.575-2.020)$ & 0.816 \\
\hline \multicolumn{3}{|c|}{ Pre-ablation $\mathrm{Tg}^{*}(\mathrm{ng} / \mathrm{ml})$} \\
\hline$<3.525$ & 1 & \\
\hline$\geq 3.525$ & $9.649(5.651-16.473)$ & $<0.001$ \\
\hline \multicolumn{3}{|c|}{ Pre-ablation $\mathrm{TSH}^{\star}(\mathrm{uIU} / \mathrm{ml})$} \\
\hline$<99.700$ & 1 & \\
\hline$\geq 99.700$ & $0.547(0.345-0.867)$ & 0.002 \\
\hline
\end{tabular}

Table 3. Risk assessments on various factors for therapeutic failure. ${ }^{\star} \mathrm{OR}=$ odds ratio, $\mathrm{CI}=$ confidence interval, $\mathrm{LN}=$ lymph node, TNM stage $=$ American Joint Committee on Cancer tumor-node-metastasis staging system, ATA risks = American Thyroid Association risks, $\mathrm{Tg}=$ thyroglobulin, $\mathrm{TSH}=$ thyroid stimulating hormone.

total thyroidectomy by our specialized thyroid surgeons. Central neck lymph node removal was conducted in all DTC patients. Unilateral or bilateral neck lymph node dissection of the lateral cervical compartments was performed if the following two conditions were met: 1) clinically or sonographically suspicious lateral lymph nodes were known, 2) pre-operative biopsy or intra-operative excision showed lymph node metastases.

After thyroidectomy, the patients came to our department for ${ }^{131} \mathrm{I}$ treatment. The included patients had the first ${ }^{131} \mathrm{I}$ therapeutic dose between 100 to $120 \mathrm{mCi}$. Our exclusion criteria were: 1 ) less than total thyroidectomy, including subtotal thyroidectomy and lobectomy; 2) thyroglobulin antibody (TgAb) $>40 \mathrm{IU} / \mathrm{mL}$ prior to the first ${ }^{131} \mathrm{I}$ therapy and post-treatment ${ }^{131} \mathrm{I}$ whole-body scan, avoiding $\mathrm{TgAb}$ 's influence on the veracity of $\mathrm{Tg}^{32} ; 3$ ) diagnostic ${ }^{131}$ I whole-body scan was performed before the first ${ }^{131}$ I therapy, ruling out possible stunning effect; 4) patients without adequate data for analysis.

The Institutional Review Board of Tianjin Medical University General Hospital approved the ethical, methodological and protocol aspects of this investigation. All DTC patients provided their written informed consents. We confirm that all methods were carried out in accordance with the relevant guidelines and regulations. 
Classification. For the purpose of our study, we defined risk constellations based on the ATA risk classification $^{3,5}$. Specifically, patients with large primary tumor $(>4 \mathrm{~cm})$ or extensive extrathyroidal invasion (T4a or T4b in accordance with the TNM system) or with distant metastases were classified as high risk. Patients with non-metastasized intrathyroidal tumors not exceeding a diameter of $4 \mathrm{~cm}$ and with $<5$ central compartment LN metastases and limited extrathyroidal invasion were classified as low risk.

Protocol. All patients were treated with ${ }^{131}$ I after a preparation of LT4 withdrawal. The patients were asked to keep a strict low iodine diet, and stop using any drug (such as amiodarone) or contrast with iodine. Routine examinations, including serum TSH, Tg, and TgAb levels and cervical ultrasound, were performed. Most of the patients received $100 \mathrm{mCi}^{131} \mathrm{I}$, only 5 patients received $120 \mathrm{mCi}$ due to imaging confirmed existence of metastasis before ${ }^{131}$ I treatment. WBS was performed 4 to 6 days later. In the follow-up treatment, all patients continued TSH suppression therapy, and regular monitoring was conducted in clinic. Further assessments of TSH, Tg, TgAb, cervical ultrasound, and post-treatment whole body scan or diagnostic whole body scan were conducted after 6 to 7 months.

Serum parameter evaluation. By chemiluminescent reaction principle, free triiodothyronine (reference $3.50-6.50 \mathrm{pmol} / \mathrm{L}$ ), free thyroxine (reference $11.50-23.50 \mathrm{pmol} / \mathrm{L}$ ) and TSH (reference $0.30-5.00 \mu \mathrm{IU} / \mathrm{mL}$, maximum $150.00 \mu \mathrm{IU} / \mathrm{mL}$ ) assays were performed on a fully automated ADVIA Centaur analyzer (Siemens Healthcare Diagnostics, New York, USA). Tg (reference 0 $-55.00 \mathrm{ng} / \mathrm{mL}$, maximum $300.00 \mathrm{ng} / \mathrm{mL}$ ) and TgAb (reference $0-40.00 \mathrm{IU} / \mathrm{mL}$, maximum $3000.00 \mathrm{IU} / \mathrm{mL}$ ) were also assessed by chemiluminescent reaction on a fully automated IMMULITE 2000 analyzer (Siemens Healthcare Diagnostics, Los Angeles, USA).

Predictors and definition. We assessed the following variables as possible influential factors for ${ }^{131} \mathrm{I}$ ablation: age, gender, primary tumor size, pathological type, capsular invasion, pathological tumor stage, LN metastasis, distant metastasis, TNM stage, ATA risks, time interval between surgery and ${ }^{131}$ I therapy, pre-ablation Tg, and pre-ablation TSH.

Disease-free status was defined as stimulated $\mathrm{Tg}<1 \mathrm{ng} / \mathrm{mL}$, negative $\mathrm{TgAb}$, and no evidence of tumor on cervical ultrasound and WBS 6 to 7 months after first ${ }^{131}$ I therapy ${ }^{5}$.

Date analysis. Analysis was performed using Statistic Package for Social Science (SPSS) version 17.0. Comparative analyses were performed using independent sample's t test or chi-square tests. Cutoff values of pre-ablation serum Tg and TSH for diagnosis were determined using ROC analysis. OR with 95\% confidence interval was calculated by adopting binary logistic regression. Logistic regression (Forward Wald method) was performed to generate an equation to check parameters' power for predicting a successful disease-free status. A P value of $<0.05$ was considered to be significant.

\section{References}

1. Siegel, R. L., Miller, K. D. \& Jemal, A. Cancer statistics, 2016. CA: a cancer journal for clinicians 66, 7-30, doi: 10.3322/caac.21332 (2016).

2. Gharib, H. et al. American Association of Clinical Endocrinologists, Associazione Medici Endocrinologi, and European Thyroid Association medical guidelines for clinical practice for the diagnosis and management of thyroid nodules: executive summary of recommendations. Journal of endocrinological investigation 33, 51-56 (2010).

3. American Thyroid Association Guidelines Taskforce on Thyroid, N. et al. Revised American Thyroid Association management guidelines for patients with thyroid nodules and differentiated thyroid cancer. Thyroid: official journal of the American Thyroid Association 19, 1167-1214, doi: 10.1089/thy.2009.0110 (2009).

4. Pacini, F. et al. European consensus for the management of patients with differentiated thyroid carcinoma of the follicular epithelium. European journal of endocrinology/European Federation of Endocrine Societies 154, 787-803, doi: 10.1530/eje.1.02158 (2006).

5. Haugen, B. R. et al. 2015 American Thyroid Association Management Guidelines for Adult Patients with Thyroid Nodules and Differentiated Thyroid Cancer: The American Thyroid Association Guidelines Task Force on Thyroid Nodules and Differentiated Thyroid Cancer. Thyroid: official journal of the American Thyroid Association 26, 1-133, doi: 10.1089/thy.2015.0020 (2016).

6. Meng, Z. \& Song, X. Reply to: Meta-analysis on Successful Ablation After Low- Versus High-Dose Radioiodine Therapy in Patients With Differentiated Thyroid Carcinoma. Clinical nuclear medicine 41, 675, doi: 10.1097/RLU.0000000000001190 (2016).

7. Song, X. et al. Different Radioiodine Dose for Remnant Thyroid Ablation in Patients With Differentiated Thyroid Cancer: A Metaanalysis. Clinical nuclear medicine 40, 774-779, doi: 10.1097/RLU.0000000000000914 (2015).

8. Fard-Esfahani, A. et al. Adverse effects of radioactive iodine-131 treatment for differentiated thyroid carcinoma. Nuclear medicine communications 35, 808-817, doi: 10.1097/MNM.0000000000000132 (2014).

9. Hakala, T. T. et al. Increased risk of certain second primary malignancies in patients treated for well-differentiated thyroid cancer. International journal of clinical oncology 21, 231-239, doi: 10.1007/s10147-015-0904-6 (2016).

10. Rosario, P. W., Xavier, A. C. \& Calsolari, M. R. Value of postoperative thyroglobulin and ultrasonography for the indication of ablation and (1)(3)(1)I activity in patients with thyroid cancer and low risk of recurrence. Thyroid: official journal of the American Thyroid Association 21, 49-53, doi: 10.1089/thy.2010.0145 (2011).

11. Rosario, P. W., Mineiro Filho, A. F., Prates, B. S., Silva, L. C. \& Calsolari, M. R. Postoperative stimulated thyroglobulin of less than 1 $\mathrm{ng} / \mathrm{ml}$ as a criterion to spare low-risk patients with papillary thyroid cancer from radioactive iodine ablation. Thyroid: official journal of the American Thyroid Association 22, 1140-1143, doi: 10.1089/thy.2012.0190 (2012).

12. Schlumberger, M. et al. Strategies of radioiodine ablation in patients with low-risk thyroid cancer. The New England journal of medicine 366, 1663-1673, doi: 10.1056/NEJMoa1108586 (2012).

13. Mallick, U. et al. Ablation with low-dose radioiodine and thyrotropin alfa in thyroid cancer. The New England journal of medicine 366, 1674-1685, doi: 10.1056/NEJMoa1109589 (2012).

14. Kendler, D. B., Vaisman, F., Corbo, R., Martins, R. \& Vaisman, M. Preablation stimulated thyroglobulin is a good predictor of successful ablation in patients with differentiated thyroid cancer. Clinical nuclear medicine 37, 545-549, doi: 10.1097/ RLU.0b013e31824852f8 (2012).

15. Gonzalez, C. et al. Thyroglobulin as early prognostic marker to predict remission at 18-24 months in differentiated thyroid carcinoma. Clinical endocrinology 80, 301-306, doi: 10.1111/cen.12282 (2014). 
16. Lee, J. I. et al. Postoperative-stimulated serum thyroglobulin measured at the time of $131 \mathrm{I}$ ablation is useful for the prediction of disease status in patients with differentiated thyroid carcinoma. Surgery 153, 828-835, doi: 10.1016/j.surg.2012.12.008 (2013).

17. Webb, R. C. et al. The utility of serum thyroglobulin measurement at the time of remnant ablation for predicting disease-free status in patients with differentiated thyroid cancer: a meta-analysis involving 3947 patients. The Journal of clinical endocrinology and metabolism 97, 2754-2763, doi: 10.1210/jc.2012-1533 (2012).

18. Vrachimis, A., Riemann, B., Mader, U., Reiners, C. \& Verburg, F. A. Endogenous TSH levels at the time of 131I ablation do not influence ablation success, recurrence-free survival or differentiated thyroid cancer-related mortality. European journal of nuclear medicine and molecular imaging, doi: 10.1007/s00259-015-3223-2 (2015).

19. Hasbek, Z. \& Turgut, B. Is Very High Thyroid Stimulating Hormone Level Required in Differentiated Thyroid Cancer for Ablation Success? Molecular imaging and radionuclide therapy 25, 79-84, doi: 10.4274/mirt.88598 (2016).

20. Winter, J. et al. Patients with high-risk differentiated thyroid cancer have a lower I-131 ablation success rate than low-risk ones in spite of a high ablation activity. Clinical endocrinology, doi: 10.1111/cen.13123 (2016).

21. Besic, N., Pilko, G., Petric, R., Hocevar, M. \& Zgajnar, J. Papillary thyroid microcarcinoma: prognostic factors and treatment. Journal of surgical oncology 97, 221-225, doi: 10.1002/jso.20935 (2008).

22. Zheng, W., Tan, J. \& Zhang, G. Extensive bone metastases as the initial symptom of papillary thyroid microcarcinoma: A case report. Experimental and therapeutic medicine 9, 2104-2108, doi: 10.3892/etm.2015.2423 (2015).

23. Chung, Y. S. et al. Lateral lymph node metastasis in papillary thyroid carcinoma: results of therapeutic lymph node dissection. Thyroid: official journal of the American Thyroid Association 19, 241-246, doi: 10.1089/thy.2008.0244 (2009).

24. Podnos, Y. D., Smith, D., Wagman, L. D. \& Ellenhorn, J. D. The implication of lymph node metastasis on survival in patients with well-differentiated thyroid cancer. The American surgeon 71, 731-734 (2005).

25. Zaydfudim, V., Feurer, I. D., Griffin, M. R. \& Phay, J. E. The impact of lymph node involvement on survival in patients with papillary and follicular thyroid carcinoma. Surgery 144, 1070-1077; discussion 1077-1078, doi: 10.1016/j.surg.2008.08.034 (2008).

26. Lundgren, C. I., Hall, P., Dickman, P. W. \& Zedenius, J. Clinically significant prognostic factors for differentiated thyroid carcinoma: a population-based, nested case-control study. Cancer 106, 524-531, doi: 10.1002/cncr.21653 (2006).

27. Leboulleux, S. et al. Prognostic factors for persistent or recurrent disease of papillary thyroid carcinoma with neck lymph node metastases and/or tumor extension beyond the thyroid capsule at initial diagnosis. The Journal of clinical endocrinology and metabolism 90, 5723-5729, doi: 10.1210/jc.2005-0285 (2005).

28. Qiu, Z. L., Shen, C. T. \& Luo, Q. Y. Clinical management and outcomes in patients with hyperfunctioning distant metastases from differentiated thyroid cancer after total thyroidectomy and radioactive iodine therapy. Thyroid: official journal of the American Thyroid Association 25, 229-237, doi: 10.1089/thy.2014.0233 (2015).

29. Lim, I. et al. Prognostic implication of thyroglobulin and quantified whole body scan after initial radioiodine therapy on early prediction of ablation and clinical response for the patients with differentiated thyroid cancer. Annals of nuclear medicine 26, 777-786, doi: 10.1007/s12149-012-0640-1 (2012).

30. Edmonds, C. J., Hayes, S., Kermode, J. C. \& Thompson, B. D. Measurement of serum TSH and thyroid hormones in the management of treatment of thyroid carcinoma with radioiodine. The British journal of radiology 50, 799-807, doi: 10.1259/0007-1285-50-599799 (1977).

31. Verburg, F. A. et al. The thyroid axis 'setpoints' are significantly altered after long-term suppressive LT4 therapy. Hormone and metabolic research $=$ Hormon- und Stoffwechselforschung $=$ Hormones et metabolisme 46, 794-799, doi: 10.1055/s-0034-1375678 (2014).

32. Spencer, C., Petrovic, I. \& Fatemi, S. Current thyroglobulin autoantibody (TgAb) assays often fail to detect interfering TgAb that can result in the reporting of falsely low/undetectable serum Tg IMA values for patients with differentiated thyroid cancer. The Journal of clinical endocrinology and metabolism 96, 1283-1291, doi: 10.1210/jc.2010-2762 (2011).

\section{Acknowledgements}

This study was supported by the National Key Clinical Specialty Project (awarded to the Departments of Nuclear Medicine and Radiology). This study was supported by Tianjin Medical University General Hospital New Century Excellent Talent Program; Young and Middle-aged Innovative Talent Training Program from Tianjin Education Committee; and Talent Fostering Program (the 131 Project) from Tianjin Education Committee, Tianjin Human Resources and Social Security Bureau (awarded to Zhaowei Meng). This study also was supported by China National Natural Science Foundation grant 81571709, Key Project of Tianjin Science and Technology Committee Foundation grant 16JCZDJC34300 (awarded to Zhaowei Meng). We thank Professor Zhenshan Jiao (a dedicated statistician from Department of Statistics, Tianjin Medical University General Hospital, Tianjin, P. R. China) for reviewing the statistical analysis of the paper. We thank Professor Jinchuan Xing (Department of Genetics, The State University of New Jersey, Piscataway, USA) for reviewing the English language of the paper.

\section{Author Contributions}

Z.M., J.T. and G.Z. designed the investigation. N.L., Z.M., Q.J., W.Z., R.W., X.L., T.H., A.U., P.Z. and S.W. conducted the investigation and collected data. N.L., Z.M., X.L. and T.H. performed the statistics. N.L., Z.M., J.T. and G.Z. wrote the main manuscript. All authors reviewed the manuscript.

\section{Additional Information}

Competing financial interests: The authors declare no competing financial interests.

How to cite this article: Liu, N. et al. Multiple-factor analysis of the first radioactive iodine therapy in postoperative patients with differentiated thyroid cancer for achieving a disease-free status. Sci. Rep. 6, 34915; doi: 10.1038/srep34915 (2016).

This work is licensed under a Creative Commons Attribution 4.0 International License. The images or other third party material in this article are included in the article's Creative Commons license, unless indicated otherwise in the credit line; if the material is not included under the Creative Commons license, users will need to obtain permission from the license holder to reproduce the material. To view a copy of this license, visit http://creativecommons.org/licenses/by/4.0/

(C) The Author(s) 2016 